\title{
Investigation of the structure, phase composition and physical-mechanical characteristics of high-strength laminated materials which contain corrosion-resistant steels with high nitrogen content
}

\author{
Evgeniia Putilova ${ }^{1, *}$, Eduard Gorkunov, Sergey Zadvorkin \\ ${ }^{1}$ Institute of Engineering Science, RAS (Ural Branch), Ekaterinburg, Russia
}

\begin{abstract}
In this work, we studied the structure, phase composition, mechanical and magnetic properties of structural steel clad with corrosionresistant steels with varying degrees of austenite stability in order to determine the possibility of using magnetic methods for diagnostics the current state of such materials.
\end{abstract}

\section{Introduction}

The development of modern industry is closely connected with the need to create and introduce new technologies and especially promising materials that are resistant to aggressive external influences and ensure the durability, reliability and cost-effectiveness of the used structures [1]. The analysis of the trends in the development of modern production shows that one of the effective solutions to this problem is the development and creation of a new generation of materials with a hierarchically organized structure, in particular multicomponent or multilayered materials. The layers or components of such materials individually have different sets of required properties, but when they are joined, it is possible to obtain a material that will combine the advantages of each layer.

So, for example, to ensure high corrosion-erosion resistance of hulls of ice navigation vessels, it is advantageous to use steels resistant to action of sea water and ice fields [2, 3]. Since corrosion wear affects only the outer surface of the hull, it is economically sound to increase the corrosion resistance of not the full hull's wall thickness but to provide it in a thin clad outer layer of corrosion-resistant steel [4]. However, the phase transformations taking place in many austenitic corrosion-resistant steels can lead to formation of new constituents in the structure of the material, which can cause deterioration in the operational properties of the product as a whole, reduce the durability and, subsequently, lead to the fracture. To ensure safety during the operation of products from laminated materials, as well as to assess the residual life of parts and structural elements, it is necessary to detect changes occurring during operational loads in the laminate as a whole as well as in its components. At present, there are only a little amount of works concerning the methods for

*Corresponding author:tuevaevgenya@mail.ru 
nondestructive testing of the current state of individual layers in bimetallic materials under operating stress conditions [5-7].

In this paper, we present the results of investigations of various laminated materials, consisting of corrosion-resistant steels with different austenite stability are present and structural steels with different strength characteristics. Also, the article shows the possibility of using magnetic parameters for estimating changes in the structure, phase composition and stress-strain state of products from the investigated materials.

\section{Experimental procedure and material}

The objects of research were various laminates based on structural steels clad with corrosion-resistant steels with varying degrees of austenite stability (manufactured by hotrolling technology "steel $11 \mathrm{CrN} 4 \mathrm{CuMoV}$ - steel $08 \mathrm{Cr} 18 \mathrm{~N} 10$ " and " steel $11 \mathrm{CrN} 4 \mathrm{CuMoV}$ steel $04 \mathrm{Cr} 20 \mathrm{Ni} 6 \mathrm{Mn} 11 \mathrm{Mo} 2 \mathrm{NVNb}$ "), and also their separate components. Both the laminates themselves and their individual components were subjected to various kinds of deformation effects: cold rolling, hot rolling, uniaxial tension.

Hot rolling, both bimetals and individual components, was carried out by several passes until the specified value of the total reduction was achieved. The value of the degrees of deformation during rolling for all materials is indicated in Table 1.

Table 1. Rolling deformation degree

\begin{tabular}{|l|c|c|c|c|c|}
\hline \multicolumn{1}{|c|}{ Material } & \multicolumn{5}{c|}{ Rolling deformation } \\
\hline steel 11CrN4CuMoV & 50 & 38 & 28 & 20 & \\
\hline steel 08Cr18N10 & 50 & 40 & 32 & 25 & 20 \\
\hline steel 04Cr20Ni6Mn11Mo2NVNb & 49 & 41 & 30 & 20 & \\
\hline «steel 11CrN4CuMoV - steel 04Cr20Ni6Mn11Mo2NVNb» & 49 & 40 & 33 & 21 & \\
\hline «steel 11CrN4CuMoV - steel 08Cr18N10» & 47 & 45 & 30 & 20 & \\
\hline
\end{tabular}

After rolling the samples were heat-treated in the following manner: quenching in water from a temperature of $950{ }^{\circ} \mathrm{C}$ and a high tempering at $600{ }^{\circ} \mathrm{C}$ during 7 hours and subsequent cooling in water. This heat treatment is usually used for the main layer - steel steel $11 \mathrm{CrN} 4 \mathrm{CuMoV}$.

Magnetic parameters were determined by means of the Remagraph C-500 magnetic measuring system. The magnetic measurements were made in a closed permeameter circuit. A magnetic field of strength up to $500 \mathrm{~A} / \mathrm{cm}$ was applied along the axis of the sample. The measurement error of the field and induction did not exceed 3\%. Before and after each measurement of magnetic properties the specimen was demagnetized. The differential magnetic permeability was determined by differentiating the descending branches of the magnetic hysteresis loop (hereinafter the figures present only those portion of the field dependences of differential permeability where peaks are formed).

The strength of the bonding of the layers in bimetals was determined by shear test of a corrosion-resistant layer by means of a Tinius Olsen machine.

Using an X-ray energy dispersive microanalysis system, Oxford INCA Energy 450 XT with a non-gas detector ADD from Oxford Instruments, the distribution of alloying elements along a line passing through two steels and an intermediate zone between them has been obtained.

X-ray phase analysis was performed on a Shimadzu XRD-7000 X-ray diffractometer.

\section{Results and discussion}


Rolling with different degrees was carried out in order to determine the minimum necessary rolling deformation to obtain a sufficiently high strength of joint. The strength of joint of the layers in bimetals was determined by the shear test of a corrosion-resistant layer. It is established that at a $20 \%$ deformation degree for both materials the shear strength of the layers is low. With an increase of deformation degree, the strength of the compound increases and it can be said that when the deformation is greater than $30 \%$ for the bimetal «steel $11 \mathrm{CrN} 4 \mathrm{CuMoV}$ - steel $08 \mathrm{Cr} 18 \mathrm{~N} 10$ » and more than $35 \%$ for the bimetal «steel $11 \mathrm{CrN} 4 \mathrm{CuMoV}$ - steel $04 \mathrm{Cr} 20 \mathrm{Ni6Mn} 11 \mathrm{Mo} 2 \mathrm{NVNb}$ » the strength does not change significantly. The maximum shear strength was determined for the material «steel $11 \mathrm{CrN} 4 \mathrm{CuMoV}-$ steel $04 \mathrm{Cr} 20 \mathrm{Ni} 6 \mathrm{Mn} 11 \mathrm{Mo} 2 \mathrm{NVNb}$ » and is $600 \mathrm{MPa}$.

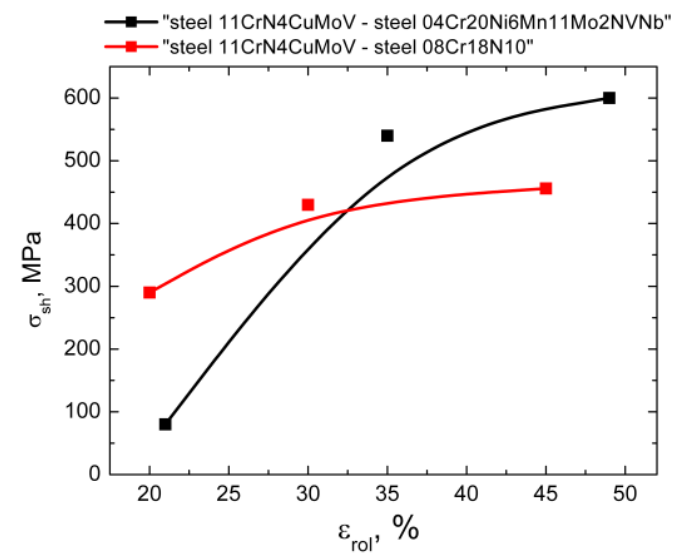

Fig. 1. Dependence of the strength joint of layers in bimetals depending on the degree of deformation by rolling

A measurement of the hardness distribution over the cross-section of the resulting bilayer materials was carried out. For the bimetal «steel $11 \mathrm{CrN} 4 \mathrm{CuMoV}$ - steel $04 \mathrm{Cr} 20 \mathrm{Ni} 6 \mathrm{Mn} 11 \mathrm{Mo} 2 \mathrm{NVNb}$ » the hardness values of both layers are approximately on the same level, however, in the transition zone (bond zone) there is the decrease of the values of hardness approximately on $20-30 \%$.

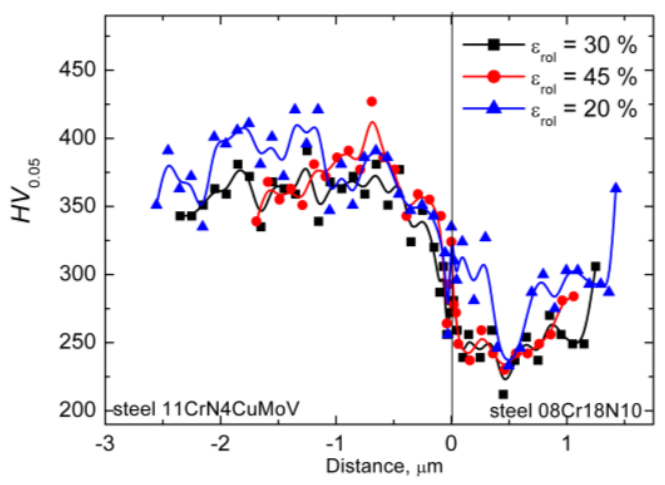

a) 


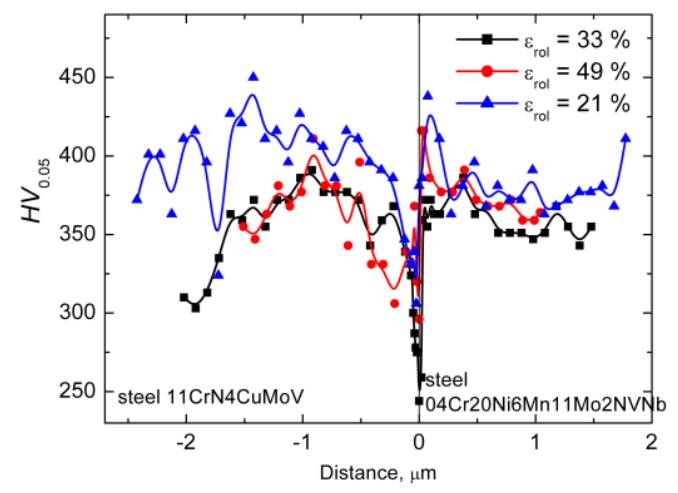

b)

Fig. 2. The hardness distribution over the cross-section of the resulting bilayer materials

The distribution of alloying elements along a line passing through two steels and an intermediate zone between them is obtained. It can be seen that in the transition region there is a decrease in such elements as chromium, nickel, manganese in the direction from corrosion-resistant steel to the main steel $11 \mathrm{CrN} 4 \mathrm{CuMoV}$. I.e. in the process of hot rolling the diffusion of chromium, nickel and manganese from corrosion-resistant steels into less doped steel $11 \mathrm{CrN} 4 \mathrm{CuMoV}$ to a depth of up to 10 microns occurs. Accordingly, corrosionresistant steels are depleted by same elements at approximately the same distance.

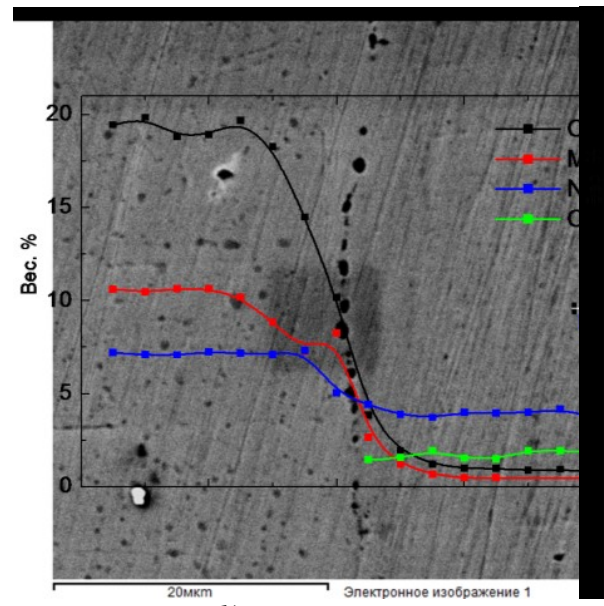

b)

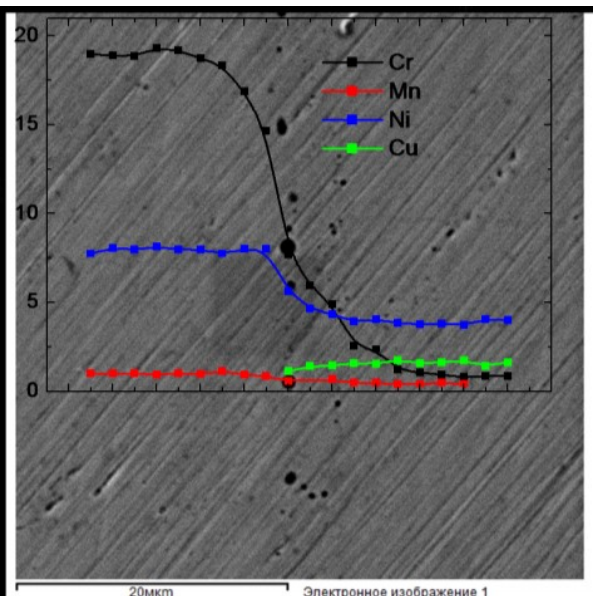

a)

Fig. 3. The distribution of alloying elements along a line passing through two steels and an intermediate zone between them

Fig. 4 for comparison shows the dependences $\mu_{\text {dif }}(\mathrm{H})$ for corrosion-resistant steel $08 \mathrm{Cr} 18 \mathrm{~N} 10 \mathrm{~T}$ [8], and $08 \mathrm{Cr} 18 \mathrm{~N} 10$, studied in this work. Figure $1 \mathrm{~b}$ shows the dependences of $\mu_{\mathrm{dif}}(\mathrm{H})$ for corrosion-resistant steel $08 \mathrm{Cr} 18 \mathrm{Ni} 10 \mathrm{Ti}$. In the initial state of $08 \mathrm{Cr} 18 \mathrm{Ni} 10 \mathrm{Ti}$ steel (Fig.4b) there is no if maximum on the field dependence due to the insufficient amount of a ferromagnetic phase in the material that is also confirmed by the X-ray diffraction analysis. However, when the strain increases, the $\alpha^{\prime}$-phase is formed [8,9] and at some value of $\varepsilon_{\text {rol }}$ a peak begins to appear on the field dependence of the differential 
magnetic permeability. The dependence of the amount of strain induced $\alpha^{\prime}$-martensite on $\varepsilon_{\text {rol }}$ for steel $08 \mathrm{Cr} 18 \mathrm{Ni10Ti}$ is practically linear (Fig. 4c), and at $\varepsilon_{\text {rol }}=0.19$ it is about $20 \%$, therefore the formation of the peak at the field dependence becomes almost immediately visible (Fig. 4b). The behaviour of the peak field for all materials is similar to that of its coercive force.

For steel $08 \mathrm{Cr} 18 \mathrm{Ni} 10$ the peak on the field dependence is formed only for the initial state sample. According to X-ray diffraction analysis the non-deformed sample contains about $10 \%$ of the ferromagnetic phase. Then this steel was subjected to hot rolling with cooling at the room temperature. Hot rolling was carried out at a temperature of $1050{ }^{\circ} \mathrm{C}$ with several passes until the specified values of the total accumulated strain been achieved. The ferromagnetic phase was absent in all the deformed samples, because of the fact that during the hot rolling the ferromagnetic phase dissolved and upon further cooling it did not have time to form. Also, in contrast to cold rolling, where the anisotropy of properties is clearly distinguished with respect to the rolling direction, it is not observed during hot rolling. The lack of anisotropy is also confirmed by the fact that the values of the residual stresses in $08 \mathrm{Cr} 18 \mathrm{Ni} 10$ steel, determined by the X-ray diffraction analysis, are practically the same level in mutually perpendicular directions.

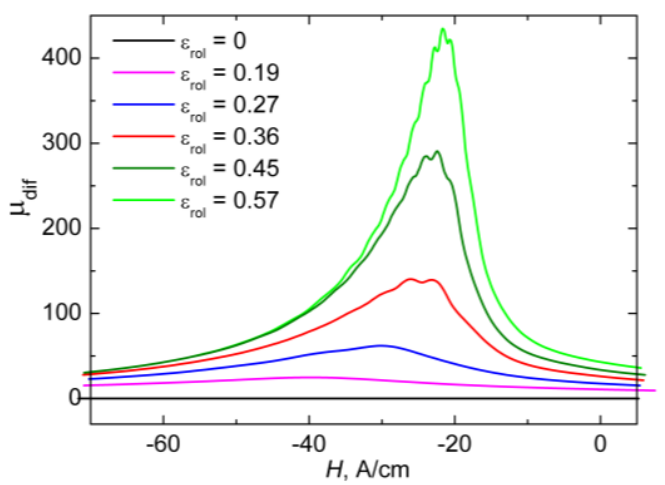

a)

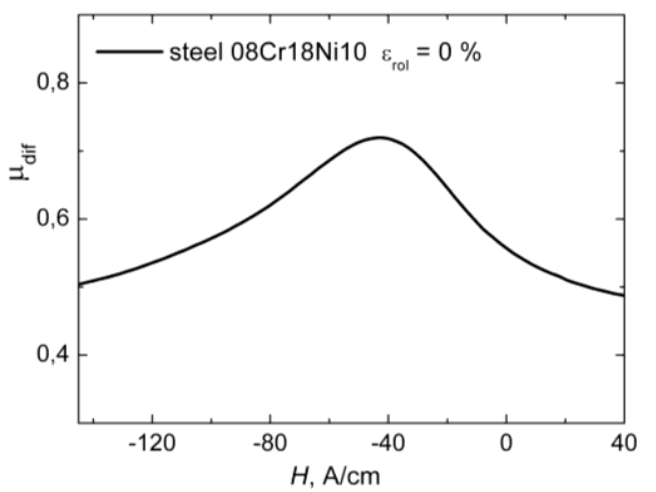

б)

Fig. 4. The field dependences of the differential magnetic permeability of $08 \mathrm{Cr} 18 \mathrm{Ni10Ti}$ (a) and 08Cr18Ni10 (b) steels

The only one peak on the field dependence corresponding to ferrite is observed for structural steel $11 \mathrm{CrNi4CuMoV} \mathrm{(Fig.} \mathrm{5a)} \mathrm{as} \mathrm{well} \mathrm{as} \mathrm{for} \mathrm{the} \mathrm{above} \mathrm{mentioned} \mathrm{steel} \mathrm{St3.}$ 
However in comparison with early studied steel St3 [8], the peak field is shifted toward higher fields, what could be explained by the more alloyed $11 \mathrm{CrNi} 4 \mathrm{CuMoV}$ steel. The peak fields (Fig. 5a) differ insignificantly, and the higher the strain, the stronger is the field the peak is located at. Figure $5 \mathrm{~b}$ shows the field dependences of the laminate "steel $11 \mathrm{CrN} 4 \mathrm{CuMoV}$ - steel $08 \mathrm{Cr} 18 \mathrm{~N} 10 "$ and its individual components. The main fig. 5b shows the curves for all materials deformed at strain about $40 \%$. It can be seen that the peak field for a laminate practically coincides with that of for $11 \mathrm{CrNi} 4 \mathrm{CuMoV}$ steel, and the field dependence for a corrosion-resistant steel does not show a peak. Thus exactly the constructional steel makes the main contribution to the formation of the magnetic properties of this laminate. As for the steel $08 \mathrm{Cr} 18 \mathrm{~N} 10$, then Fig. $5 \mathrm{~b}$ shows the peak in the field dependence of the differential magnetic permeability of this steel in the initial state. As already mentioned above, in addition to the austenite there is ferromagnetic phase in the initial state of the steel $08 \mathrm{Cr} 18 \mathrm{~N} 10$. However, with further hot rolling at $1050{ }^{\circ} \mathrm{C}$, these phases decompose, so one can not observe any peaks in the field dependence after rolling.

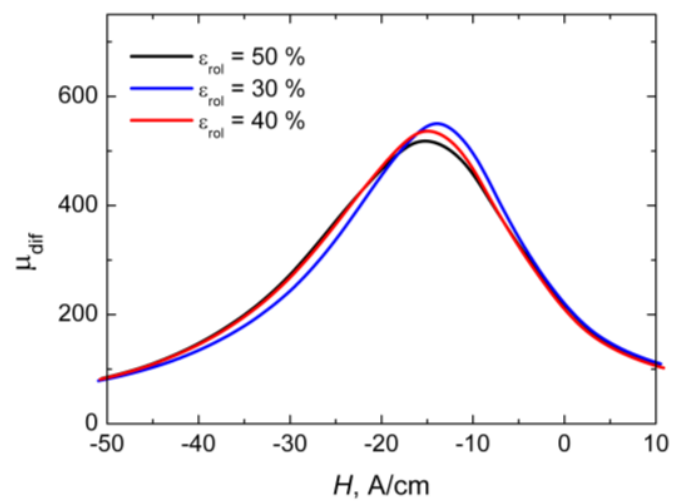

a)

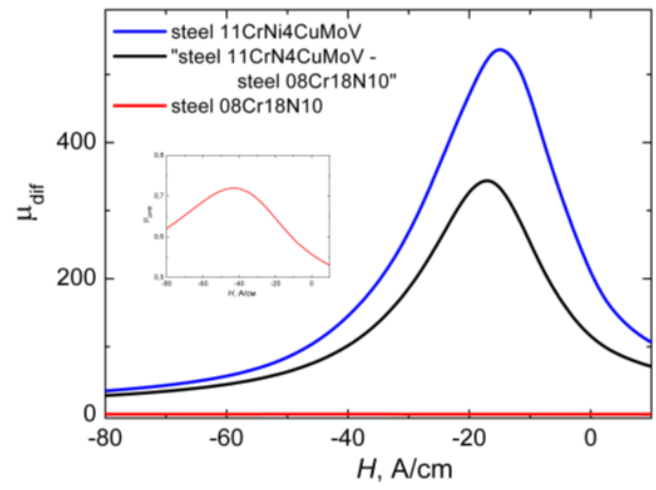

б)

Fig. 5. The dependences of $\mu_{\mathrm{dif}}(\mathrm{H})$ for the steel $11 \mathrm{CrN} 4 \mathrm{CuMoV}$ with different rolling strains (a); the steels $11 \mathrm{CrN} 4 \mathrm{CuMoV}, 08 \mathrm{Cr} 18 \mathrm{Ni10}$ and the laminated material made from these steels (b)

Figure 6 shows the field dependencies of differential magnetic permeability for specimens of $11 \mathrm{CrNi} 4 \mathrm{CuMoV}$ steel and laminates "steel $11 \mathrm{CrN} 4 \mathrm{CuMoV}$ - steel $08 \mathrm{Cr} 18 \mathrm{~N} 10 "$ and " steel $11 \mathrm{CrN} 4 \mathrm{CuMoV}$ - steel $04 \mathrm{Cr} 20 \mathrm{Ni} 6 \mathrm{Mn} 11 \mathrm{Mo} 2 \mathrm{NVNb}$ " at the maximum strain accumulates after hot rolling. All the curves clearly show one peak corresponding to the ferrite in the structural steel $11 \mathrm{CrN} 4 \mathrm{CuMoV}$. 


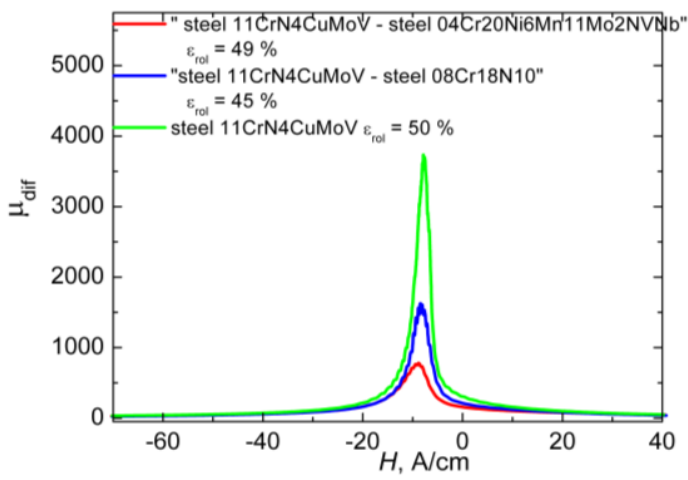

Fig. 6. The dependences of $\mu_{\text {dif }}(\mathrm{H})$ for the steel $11 \mathrm{CrN} 4 \mathrm{CuMoV}$ and laminates "steel $11 \mathrm{CrN} 4 \mathrm{CuMoV} \quad-$ steel $08 \mathrm{Cr} 18 \mathrm{~N} 10 ", \quad "$ steel $11 \mathrm{CrN} 4 \mathrm{CuMoV} \quad$ - steel 04Cr20Ni6Mn11Mo2NVNb" under maximal deformation

\section{Conclusion}

The microstructure, phase composition, mechanical and magnetic properties of two-layered joints of high-strength steel and corrosion-resistant steels with different degrees of austenite stability obtained by hot rolling are studied. The strength joint of the layers was estimated by means of shear tests. It is shown that at higher strain degrees the strength of the joint increases. The possibility of diagnostics of the formation of a magnetically ordered phase in austenitic steels by the maximum magnetization in the maximum applied field (saturation magnetization) and the maximum magnetic permeability, during hot rolling and further heat treatment is established. It is shown that the coercive force and the maximum magnetic permeability can be used as parameters of non-destructive testing to assess the quality of such heat treatment operations as quenching and tempering of the materials under study.

It is shown that the value of the maximum differential permeability can be used for the controlling the strain-induced phase transformations in corrosion-resistant austenitic steels constituting a macroscopically inhomogeneous material. The values of the maxima on the field dependences of the differential magnetic permeability can be used as parameters to detect the formation of a new magnetically ordered phase during plastic and elastoplastic deformation, as well as its amount. The field values that correspond to the peaks on the field dependences of the differential magnetic permeability can be used to estimate the strain accumulated by rolling and uniaxial tension of corrosion-resistant metastable steels.

The work was partially supported by the RFBR, grant No 16-38-60027 and performed within the state task, No 01201354598. The researchers used the equipment the "Plastometriya" collective use center.

\section{References}

1. M.V. Kostina, O. A. Bannykh, V.M. Blinov, E. V. Blinov, V. N. Karpov, Almanac of Clinical Medicine 17, 2, 92-95 (2008).

2. V.V. Sagaradze, N.V. Kataeva, S.Y. Mushnikova, O.A. Khar'Kov, G.Y. Kalinin, V.D. Yampol'Skii, Phys.metals metallog. 2 ,115, 202-210 (2014). 
3. N. Nesterov, Morskoy flot 5, 24-28 (2005).

4. S.Y. Mushnikova, V.A. Malyshevskii, G.Y. Kalinin, S.K. Kostin, V.V. Sagaradze, Y.I. Filippov, N.V. Kataeva, V.A. Zavalishin, Phys.metals metallog. 6 ,116, 626-635 (2015).

5. M.B. Rigmant, A.P. Nichipuruk, M.K. Korkh, Russ. J. Nondestr. Test. 9, 511-521 (2012).

6. M.B. Rigmant, A.P. Nichipuruk, B.A. Khudyakov, M.K. Korkh, S.A. Zinchenko, A.V. Zagainov, Russ. J. Nondestr. Test. 10, 583-587 (2016).

7. A.P. Nichipuruk, B.A. Khudyakov, M.K. Korkh, M.B. Rigmant, V.G. Kuleev, Russ. J. Nondestr. Test. 6, 405-409, (2009).

8. E.S. Gorkunov, S.M. Zadvorkin, E.A. Putilova, A.M. Povolotskaya, L.S. Goruleva, I.A. Veretennikova, I.S. Kamantsev, Russ. J. Nondestr. Test. 6, 346-356 (2012).

9. E.S. Gorkunov, S.M. Zadvorkin, E.A. Kokovikhin, E.A. Tueva, Yu.V. Subachev, L.S. Goruleva, A.V. Podkorytova, Russ. J. Nondestr. Test. 66, 369-380 (2011). 